\title{
HIGH HAZARD OBJECTS EXPLOITATION IN RURAL REGIONS AND IDENTIFIED RISK MANAGEMENT PROBLEMS IN LATVIA
}

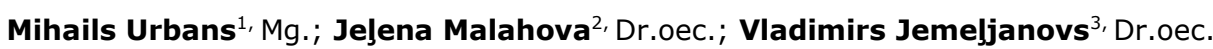

$1,2,3$ Riga Technical University, Institute od Occupational Safety and Civil Defence

\begin{abstract}
The deployment of potentially dangerous objects often results in criticism from urban dwellers around the world. Often these objects are not only in urban areas but also in rural areas. Accidents at such objects often lead to deteriorating living conditions, as well as to impossibility to use land and water resources, and uncontrollable environmental pollution. There are many different studies across the world in this area, but the situation in Latvia related to the management and prevention of technogenic risks has not been studied. The article considers particular qualities of high hazard objects' exploitation particular qualities in rural areas of Latvia. Management of technogenic risks is studied and assessed as an independent management system and its role is specified in the development of Latvian rural regions as well as the management risks are identified and possible harmful consequences for the inhabitants and environment. The present article reviews a situation how high hazard objects are exploited in Latvia, what management drawbacks are established and what are the possible solutions. The aim of the study is to show the link between the operational factors and environmental impacts of increased hazard sites, as well as to examine the management system, the prevention of existing hazards and to identify risks. The study results in the demonstration of identified situation and shortcomings in technogenic risk management system and their impact on the rural environment.
\end{abstract}

Key words: high hazard objects, environment protection, civil defence, disasters.

JEL code: R19, L89

\section{Introduction}

The deployment of potentially dangerous objects often results in criticism from urban dwellers around the world. Often these objects are not only in urban areas but also in rural areas. Many of the consequences of the accidents, carried by many technogenic objects and, potential danger zones have long exceeded certain small regions; and accidents in Bhophale, Fukusima, Seveso have become synonymous for fear around the world. Accidents at such companies often lead to deteriorating living conditions, as well as to impossibility to use land and water resources, and uncontrollable environmental pollution. There are many different studies across the world in this area, but the situation in Latvia related to the management and prevention of technogenic risks has not been studied.

69 objects are located in the territory of Latvia where operations with hazardous chemicals are carried out in such a volume that these facilities fall within the European Parliament and Council Directive 2012/18/ES (04.07.2012.) on the management of high risks of accidents associated with hazardous substances. The industrial accident objects include 39 lower risk level objects and 30 higher risk level objects. All abovementioned objects are potentially dangerous and, upon coincidence of certain circumstances, an accident can occur at them threatening the neighbouring people, technologies and environment.

The aim of the study is to show the link between the operational factors and environmental impacts of increased hazard sites, as well as to examine the management system, the prevention of existing hazards and to identify risks. The study results in the demonstration of identified situation and shortcomings in technogenic risk management system and their impact on the rural environment.

The objectives are to examine existing data on the management of technogenic risks in the field of industrial security in Latvia and the EU; explore regulatory enactments governing industrial security from the point of view of the Latvian civil protection system; draw conclusions on the 
shortcomings of the industrial security system and its effects on the rural environment in Latvia. Methods applied in the study are deduction and comparison methods. Through the deduction method, the authors will examine all the components of the legislation on industrial safety related to the management of emergency prevention in Latvia. The method of comparison will be used as proof of the existence of problems in managing risks and for comparison with the optimal situation

\section{General}

Disaster risk reduction is a broad term which encompasses many human actions that either prevent or limit the devastating human, infrastructure, and financial impacts of disasters (Organisation..., 2011). In order to achieve the development and stability of agriculture, also in relation to a possible effect of disasters, in 2013 the Ministry of Agriculture of the Republic of Latvia and LLKC "Latvian Rural Advisory and Training Centre" have developed an important document for the development of the entire Latvian agriculture titled "Activities for the rural space long-term strategy, description of agricultural situation and analysis of the industry needs for the development of the Latvian Rural Development Plan 2014-2020". In accordance with this document, it has been identified that the agriculture is an in important sector of Latvian national economy as well as provides the urban inhabitants with food supply and is the main maintainer and guardian of the environment quality (Activities, 2013). In this context, it is important to preserve Latvian agricultural lands against the technogenic threat and not deteriorate the environmental conditions, thus providing a possibility to preserve the quality of life and land resources for the next generations. In Latvia, the high hazard facilities (hereinafter referred to as HHF) that are engaged in storage, transportation or manufacture of hazardous and harmful substances are located not only in towns but also in rural regions, as well as the railway and motor-road infrastructure crosses all regions of Latvia.

The risk of possible accidents at HHFs, which could lead to a technogenic disaster and adverse consequences, can be not only in the vicinity of HHF but also at considerable distances, thus creating the environmental and social risk among the inhabitants who very often are not aware of potential threat and are not prepared to overcome the possible consequences with their own resources; Latvian farmers often lack money reserves and in case of pollution will not be able to eliminate the harmful consequences with own resources. Threat unawareness about the harmful consequences and possible scope thereof exists also on the level of governmental organizations that are responsible for the control of industrial risks and assessment of documents. The world practice gives evidences that preventing a threat is more efficient than coping with the consequences. Restoration is generally a costly undertaking, partly because it is often begun only after environmental degradation is well developed and is expensive to avert, but also because it is often labour and resource intensive. Furthermore, restoration often requires large investments upfront and has long lags before generating benefits (Crookes, 2013). Thus, at the national and local government level in Latvia, it is necessary to timely plan the protection measures and identify the possible risks in order to reach a stable development and growth of Latvian rural regions without spending great money resources for liquidation of consequences, which also is a timeconsuming process. The technogenic risk management is an urgent problem all over the world and Latvia is not an exception. Efforts in the field of disaster and emergency management have shifted towards a focus on disaster risk reduction with the overall goal of increasing capacities in both rural and urban contexts (Cole, 2014). Imbalance in social awareness of ecological and technogenic 
risks, which is currently evident in Latvia and already for a long time being the reason for doubts and nonunderstanding among people who are responsible for the management of such risks, has led to the studies of the risk perception.

Previous studies on the relation between real and perceived risks were analysed by the challenge response model. It was hypothesized that people are concerned about environmental hazards because they need to cope with "out there" yet objectively identifiable problems (Inglehart, 1995). In Latvia in 2015, the Ministry of Environment and Regional Development carried out the study "Assessment of disaster possibility and effect risks in environment" that demonstrated well that considerable problems exist in the country with the risk assessment and action algorithms, which creates disagreements in risk management between the state institutions, local governments and enterprises. Also the time went by since the assessment and necessary amendments were made in some regulatory enactments, the lasting entropy and large stock of issued regulations have resulted in fact that all necessary measures are taken, which is explained also by the failure to develop a unified risk assessment methodology that would allow to work out a unique approach to the branch risk assessment. Risk analysis methods, along with postconstruction standards currently being developed, are evolving tools aimed at helping companies maintain plants better and save money (Degaspary, 2002).

According to previous studies in Europe, the industrial risk management is based on the identification of possible threats. The objective is the restriction, guard and safety with technical, human and financial resources of the organization. Enterprises where a high risk of accidents exists are subject to the administrative duty to carry out own labour risk assessment for any hazardous material used, manufactured or stored; however, there is no unified methodology in Latvia for risk evaluation and thus the enterprises themselves can decide what risk assessment system will be used and what results will be required. Legal regulation of these systems in Latvia is generally controlled by the State Environmental Supervision Bureau, the State Environmental Service and the State Fire and Rescue Service as a part of the civil defence system (hereinafter referred to as $C D$ ). In order to understand how this system is functioning, in the next section the authors will analyse in detail the general industrial safety mechanism in Latvia and will identify the drawbacks in the risk management. Studies carried out within more than thirty years provide few strategies for the management of environmental threats. Various authors identify contradictory risk management concepts, realistic ones that explain the risk as a physical reality existing regardless of our knowledge about it, and those explaining the risk as a social structure with an emphasis on the contrast risk assessment and social quality (Vandermoere, 2008).

\section{Safety of industrial facilities as part of civil defence}

Industrial safety is a state of protection of vital interests of the society and the lives of employees against accidents and their consequences in hazardous production facilities. In turn, labour protection, electrical safety, and fire safety are part of the industrial safety.

In each company, one of the main tasks is to identify potential hazards, sources of risks (internal ones that may occur in the company itself and external ones that exist irrespective of the operation of the facility), plan and take measures to prevent or minimize risks to employees, damage to property and the environment. It is important for the people of each facility and surrounding areas to be aware of the danger they are exposed to. They need to understand where there is a danger that can be detrimental to them, what is the real state of affairs, how to protect 
themselves against the effects of harmful and dangerous environments. A threat according the European Commission Staff Working Paper is a dangerous phenomenon, substance, human activity or circumstance that can lead to loss of life, injury or other damage to health, damage to property, loss of livelihood and services, social and economic destabilization, or damage to the environment (Riska..., 2010).

In order to better manage the State of Exception (hereinafter referred to as SE) in any company, it is necessary to develop the ES management plans, including the maximum possible number of threats and the operational algorithms.

One of the main tasks in any company is to provide a safe working environment for its employees, but along with normal situations at work dangerous situations can be created threatening all employees of the facility or, in some cases, the inhabitants outside the facility. Dangerous condition of a facility is a state that does not turn into breakdowns or into an extremely dangerous condition provided the servicing personnel is acting in a modern and proper manner (Smidre, 2008).

In accordance with laws and requirements of the CM regulations, each high hazard facility (hereinafter referred to as the HHF) shall develop the CD Plan of the facility, the Safety Review (hereinafter referred to as the SR) or the Accident Risk Prevention Programme (hereinafter referred to as the ARPP), depending on the amount of hazardous substances in the facility. In accordance with Article 15 of the CAKPL, local governments shall publish on their Internet homepage the HHF CD Plan and shall ensure that it is actual. The SFRS shall develop the HHF - Out-of-facility CD plans where measures and resources are provided for, which are necessary to overcome possible breakdown or accident of which consequences can spread beyond the territory of the Facility. For each HHF existing in Riga, the SFRS has developed the CD plans of the facility, which are a component part of Riga CD Plan. There in total 18 HHFs of regional and national level in Riga, which have developed the CD plans, SR or ARPP in accordance with the CM Regulation No. 131 of 01.03.2016. "Industrial accidents risk assessment procedure and rick reduction measures" (hereinafter referred to as the CM 131), this regulation providing also for the systematic control of the facilities and requirements necessary for execution by management of the Facilities in order not to allow the emergency situation as well as to mitigate possible adverse consequences.

According to explanation given in the book "Labour Safety", the SE is divided into: threat of SE, partial SE, general SE, evacuation. Threat of SE: such situation can be neutralized by means that are provided for firefighting and with help of personnel present at the place of accident. Partial SE: it cannot be liquidated as easy as the previous one since personnel present at the place of accident will need help of a qualified team that is better prepared and has at its disposal more means to cope with fire and emergency circumstances. General SE: its size exceeds the possibilities of human resources and materials at their disposal in coping with fire and emergency circumstances. It disturbs the everyday working rhythm of the enterprise and it is necessary to call for help from outside. Evacuation: SE when it is necessary to partly or fully remove the personnel from the enterprise premises or territory, consistently and under control (Darba..., 2010).

In order to reduce the occurrence of SE at the facility, the Labour Protection (hereinafter referred to as LP) Law establishes the responsibilities for the employers to care of their employees, forming the rapid response teams, including therein the trained employees, upon threat of emergency or occurrence of the SE. Article 12 "First aid and other emergency measures" of the LS Law establishes as follows: 
(1) The Employer at the enterprise shall provide measures necessary for rendering first aid, confinement or liquidation of dangerous consequences of equipment breakdown, firefighting, evacuation of employees and other persons.

(2) The Employer:

1) shall ensure the communication with external services, particularly with service providing emergency medical aid and carries out firefighting and rescue works;

2) shall appoint employees trained in first aid, performance of firefighting and personnel evacuation measures, and shall ensure that these employees are in a sufficient number, respectively instructed and provided with necessary equipment (Darba..., 2001).

In accordance with the above, the employer, regardless of whether the enterprise is or is not referred to the HHF, shall be liable to meet the requirements of the LS Law and appoint the personnel, purchase the respective equipment as well as to carry out training of the personnel in case of the SE. If threat of the SE at work is not eliminated in full, then the employer shall be barred from demanding the employees to resume work if all measures have not been taken to prevent the threat and ensure safe work.

When developing the SE action plans, the HHF management has all possibilities to reduce the possible risk at workplaces and damages to the enterprise, which are caused by adverse consequences. These adverse consequences for the enterprise can be both economic and public when information is spread in media, which causes a wide response in the society. But in general, all adverse consequences will result in the reduced volume of manufactured products, which can lead to a bankruptcy.

Thus, carrying out the SE probability analysis, the HHF management can timely develop all necessary instructions, acquaint with them the personnel, appoint employees for performance of actions to cope with the accident, thus reducing the risk and probability of occurrence of adverse consequences. It is worldwide recognized that in combat with the SE the best device is the performance of preventive measures at the enterprise, which minimize all kinds of damages.

In order to reduce the probability of the SE occurrence, a job instruction with description of employee's responsibilities and main tasks should be developed for each position in which the employees work. Thus the job description will help the employee to understand the general situation and the complexity of the contracted work, and so to evaluate whether (s)he will be able to carry out the responsibilities.

The most widespread SE that can occur at the enterprise is fire. In order to prevent fire breakout, various safety measures should be taken.

With the objective to reduce the fire threat to the enterprise and employees, the CM Regulation No. 238 of 19.04.2016 "Fire safety regulations" is issued establishing the liability to develop a fire safety instruction including the information on actions in case of fire. Article 175 of the fire safety regulation specifies that the responsible person shall ensure the development of the fire safety instruction for an economic activity facility or a public facility (except undeveloped territory and territory where construction is not carried out). The fire safety instruction is a complex of fire safety requirements meeting the designated use of the economic activity facility or the public facility. The enterprise shall be required to develop the instruction if the facility meets article 192 of the fire safety regulation, which provides for the economic activity facility or the public facility where more than 50 people can be present at the same time. Responsible person of a critical infrastructure facility not rarer than once a year shall arrange practical studies in accordance with 
the fire safety instruction section "Actions in case of fire". In addition to the abovementioned, the employer shall be liable to develop also the evacuation plans and place them in the enterprise premises. The evacuation plan means visually executed unambiguous instructions how a natural person should act in case of fire, breakdown or dangerous situation and how possibly faster get to a safe location (Ministru..., 2016).

Based on the abovementioned, it shall be concluded that $100 \%$ of enterprise should have the fire safety instructions while the evacuation plans shall only be developed in cases when the enterprise meets criteria specified in article 192 of the fire safety regulation.

With the objective not to allow the fire break-out at the enterprise and reduce the possibilities of injuries to the employees, the CM Regulation No. 209 of 12.04.2016 were adopted: "Equipment electrical safety regulations" providing and establishing the essential requirements for electrical equipment and the mechanism for supervision of their observance as well as the procedure of marker supervision. Observance of this regulation cam considerably reduces the possible risks for the enterprise and employees.

If the enterprise is a HHF, then it shall develop the ARPP as well as the CD plan, which also make up the biggest part of materials proving the expediency of the industrial safety measures at the enterprise.

Currently, at all enterprises that are not the HHF, in order to anticipate the possible threats, identify the risk sources and coordinate actions in case of breakdown or disaster as well as to plan and take other preventive, preparatory, response and consequence liquidation measures, the CD plan should be worked out in accordance with the CM Regulation No. 658 of 7 November 2017 "Regulations on the structure of civil defence plans and information to be therein included". CAKPL, being in force since 1 October 2016, provides to ease the administrative burden on the entrepreneurs and specifies that the CD plan shall only be developed by the HHFs. In this situation, the fuel filling stations (hereinafter referred to as the FFS) and gas filling stations (hereinafter referred to as the GFS), which are important facilities of national economy, lose their significance within the framework of the $C D$ system since in case of threat the owner does not provide a special action algorithm as well as the general NS system safety, see Figure 1.

The CD plan should necessarily have therewith enclosed the annex "Plan of action in case a substance or object of unknown origin is found". This plan provides for action by employees if a substance of unknown origin is found, or suspicious or explosive object is found, suspicious postal item is received (unopened, damaged, partly opened), which arouses reasonable suspicions of presence therein of unknown origin substance, suspicious or explosive objects, known fact pointing to the threat of explosion or terrorism, information is received about possible release of hazardous substance.

In addition to the abovementioned documents, the enterprise management shall have the right to conclude cooperation agreements on mutual assistance and overcoming the SE with other enterprises, thus reducing the adverse consequences, for example, in cases of sanation.

Within the CD plan, DR and ARPP, the employees should be provided with the possibility to receive all information necessary to prepare for overcoming any SE at the enterprise by respective efforts and resources.

The safety assurance system includes also systems specially established with the objective not to allow the SE occurrence or to minimize adverse consequences, which could be automatic fireextinguishing systems, collective protection means. The collective protection means include: fire- 
extinguishing systems, alarm and warning systems, damaged process shutdown systems, monitoring systems.

The firefighting system today is a combination of complex engineering measures that can ensure the fire safety of a building and industrial facility and technical equipment combined into systems for rapid detection and eradication of fire. Such fire safety assurance means include fire alarm systems, smoke prevention systems and fire extinguishing systems. The fire-fighting system helps to ensure fire safety of the facility and eliminate the possibility of uncontrolled fire occurrence. Automatic fire extinguishing systems detect fire in a timely manner and eliminate the fire in its early stages of development. They work automatically upon receiving a signal of fire in the protected area. There is a wide range of fire detection systems that employers can choose themselves depending on the characteristics and security class of the enterprise.

Alarm and warning systems are important when an enterprise faces a dangerous situation and it is necessary to notify its employees and visitors, therefore the importance of this system is extremely high. The warning system is mostly used jointly with the fire detection and alarm system because it is possible to efficiently evacuate people through voice announcements.

Damaged process shutdown systems are important at enterprises where production processes take place, the system follows the ongoing processes and, if necessary, automatically shuts them down thus preventing the occurrence of the SE.

Monitoring systems allow the operator to follow the situation, remotely and if necessary to shut down the work processes. It can be done by video surveillance cameras, detectors etc.

In the present study, the authors have examined the CD plans of 19 Riga HHFs and have found out that the approach to the industrial safety measures depended on position of the facility management and available financing. Educational level and responsibility factors differ as well, depending on the following aspects: preparation of documents and actual situation at the facility. Often the facility administration's position in relation to the safety system management and quality of documents is formal. And namely, information that is reviewed in the CD plan does not coincide with information delivered in the SR or ARPP since persons responsible for the safety measures interpret the CM regulations in a different way, as a result of which it leads to a chaotic organization of the industrial safety at the facility. Each document itself may be developed in full volume and in accordance with the effective legislation; however, analysing the common parallels and comparing the safety measures at the facility, it was established that the production facilities are often featured by a chaotic approach and lack of communication between structural units. One of entropy formation factors is also enterprises providing services on contractual basis only within a narrow specificity, for example, on LP or only on firefighting, thus situations occur when the facility documents have been developed by several competent institutions but there is no common connection between the documentation and fulfilment of measures at the facility. Checking each component of the system individually, members of the State Environment Service inspection commission formed at a HHF only look at their sphere, for example, labour protection or fire safety.

The inspecting institutions have possibility to make sure of the complex of measures only from the CD plan, SR or ARPP, which are voluminous documents and serve as a summary of all HHF safety documents. It can be stated that the State Environment Supervision Bureau (hereinafter referred to as VPVB), examining the SR or the ARPP or HHFs, establishes very many deficiencies in the safety system, which should be eliminated by the HHFs, thus evidencing a situation when the facility management has no responsibility for the correctness of submitted documents and for the 
possibility to fulfill the complex of safety measures. VPVB serves as a school teacher who checks the work of a bad pupil who is not responsible for correctness and accuracy of own work. The problem situation is also deteriorated since VPVB, assessing the SR or ARPP of enterprises, prescribes a period of several years for elimination of drawbacks while HHFs take advantage of this situation and do not eliminate the drawbacks as long as possible but postpone until the last moment.

Importance of the HHF CD plan in the context of documents is minimal and it briefly repeats information available in the SR or ARPP, this situation became possible since the CD plan is developed based on the CM Regulation No. 131 issued in accordance with the Chemicals Law, which is not an efficient measure of the facility protection in the context of the ML, ASIS and NS law. Protective content of the $C D$ is fully ignored while it is an efficient complex of measures protecting the facility against external hazard sources. Usually the section "external threats" is developed formally and does not provide for whatever complex of actual measures in activity of the facility in order to efficiently reduce the threat to the facility infrastructure and not allow the occurrence of emergency situation (such as masking measures). At present time, the HHFs limit themselves to the closing measures, which from the standpoint of the CD system is not a correct way out of the possible risk threat situation and provision of national economy with raw materials. Closing large oil storage HHFs means a chain reaction in activity of all nation economy sectors, for example, fuel supply is an important function in population evacuation, food supply and operation of special services.

HHF safety and action algorithm development from the standpoint of the CD system measures efficiency is an integral part of the NS system, but at present time this issue of the CD system is developed very poorly and the planned closing measures are inefficient, which means unassured stability of national economy.

Regularities of the CD systems from the standpoint of the SE probability and the system stability are shown on Figure 1. The illustrated situation at minimal level demonstrates the importance of mutual functional dependency of many structures.
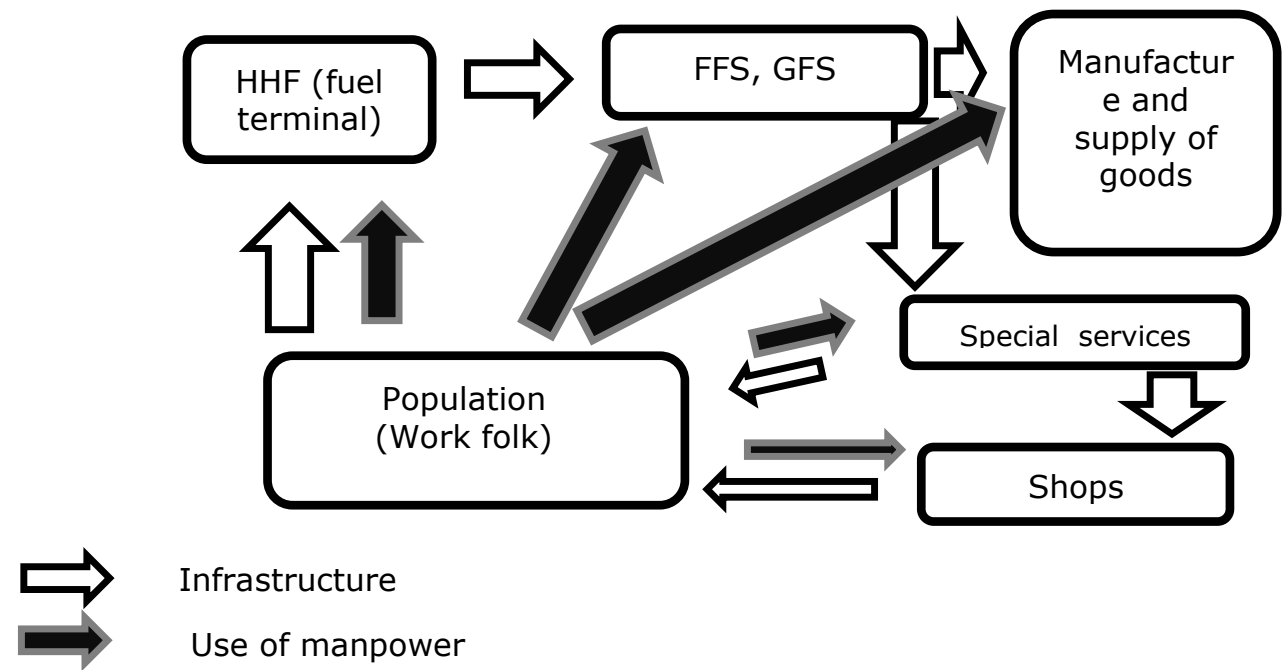

Source: author's work

Fig. 1. Minimal national stability (within CD system)

Within the system stability, it is important to retain each involved element but the most important function is with the basic enterprises, on which the existence of other institutions and inhabitants depends, therefore the most part of HHFs working in order to provide local market with 
source materials are important objects of national economy, which must be preserved and functioning of which must be ensured in cases of threat. National CD system should be provided with a complex approach on the part of the entire society since liquidation of one element causes problems in other ones.

\section{Conclusions}

1) The management system, regulatory enactments regarding the safety of the functioning of dangerous industrial enterprises in Latvia, system of control from the supervisory institutions and shortcomings contained in the risk management system have been examined.

2) Latvian agriculture development and environment preservation are closely connected with the HHF safety system and measures carried out to reduce the possible accident risk.

3) In general, HHF stability depends on both the quality of regulatory enactments issued by the governmental institutions and the approach of the enterprises to the safety solutions. Development of Latvian agriculture is closely associated with the HHF safety measures and realizable risk identification policy.

4) More institutions are established in Latvia, which carry out complex HHF inspections, but each institution only reviews the safety measures within its competence, which results in an observable situation with empty sectors when a general picture of the safety system and adequate risk assessment are not developed.

5) HHF safety is closely associated with the functioning of Latvian civil defence system that ensures the protection of inhabitants in case of accident or disaster.

6) Environmental impacts may be catastrophic in the event of an accident; thus, the management of high-risk companies is obliged to comply with the requirements of national supervisory authorities, which not always occurs.

7) The correlation between the quality of the documents to be developed and the safety of an increased hazard company directly affects the company's ability to prevent and identify harmful environmental consequences. There is a possibility of reducing potential technological risks and potential impacts on the rural environment, which often depends on the quality of the inspections carried out by the supervisory authorities and the necessary measures taken by the managers of high-risk enterprises.

\section{Bibliography}

1. Aktivitates lauku telpas ilgtermina strategijai Lauksaimniecibas situacijas apraksts un nozares vajadzibu analize Latvijas Lauku attistibas plana 2014.-2020. gadam izstradei. (Activities for the long-term strategy for the rural area of agriculture and analysis of the needs of the industry for the development of the Latvian Rural Development Plan 2014-2020) (2013). pp. 4.

2. Cole, J.M., Murphy, B.L. (2014). Rural Hazard Risk Communication and Public Education: Strategic and Tactical Best Practices. International Journal of Disaster Risk Reduction. Volume 10, Part A. pp. 292-304.

3. Crookes D.J., Blignaut, J.N., ,M.P. de Wit, Eslerd, K.J., Le Maitre, D.C., Milton,S.J., Mitchell, S.A., Cloete, J., De Abreu., P, Fourie (nee Vlok), H., Gull, K., Marx, D., Mugido, W., Ndhlovu, T., Nowell,M., Pauw M.,, Rebelo, A. (2013). Journal of Environmental Management, Volume 120, pp. 138-147.

4. Darba aizsardzibas likums. (Labour Protection Law) (2001)// "Latvijas Vestnesis", 105 (2492).

5. Darba drosiba. (Occupational Safety) (2010). Riga: LR Labklajibas ministrijas izdevums. pp. 271.

6. Degaspary, J. (2002). Risky Business: Practitioners Say That the Techniques for Managing Industrial Risk Also Protect the Bottom Line. (Feature Focus: Plant Safety) Mechanical Engineering-CIM. Volume 124(7), pp. 42-43

7. Inglehart, R. (1995). Public Support for Environmental Protection: Objective Problems and Subjective Values in 43 Societies. Political Science and Politics, 28(1), pp. 57-72.

8. Ministru kabineta noteikumi Nr. 238 "Ugunsdrosibas noteikumi" (Ministry Cabinet Regulations Nr.238 "Fire Safety Regulations") (2016). //"Latvijas Vestnesis", 78 (5650). 
9. Organisation for Economic Co-Operation and Development, Risk Awareness, Capital Markets and Catastrophic Risk. (2011) Policy Brief Policy Issues in Insurance No. 14. Retrieved from (http://dx.doi.org.resursi.rtu.Iv/10.1787/9789264046603-en〉. Access: 20.10.2016.

10. Riska novertesanas vadlinijas katastrofu parvaldibai. (Risk assessment guidelines for disaster management) (2010). Brisele: Komisijas dienestu darba dokuments. pp. 8.

11.Smidre,P., Jemeljanovs, A., Ievins, J., (2008). Vides aizsardziba no tehnogeno avariju un katastrofu generetajiem piesarnojumiem. (Environmental protection from technology-generated pollution and disastergenerated pollution) pp. 42.

12. Vandermoere, F. (2008). Hazard Perception, Risk Perception and Need for Decontamination by Resident Exposed to Soil Pollution: The Role of Sustainability and the Limits of Expert Knowledge. Risk Analysis. Volume 28(2), pp. 387-398 